\title{
Changes in the clinicopathological characteristics and genetic alterations of follicular thyroid cancer
}

\author{
Young Shin Song',*, Jung Ah Lim²,*, Hye Sook Min³, Min Joo Kim', Hoon Sung Choi ${ }^{4}$, Sun Wook Cho', \\ Jae Hoon Moon ${ }^{5}$, Ka Hee Yí ${ }^{6}$, Do Joon Park ${ }^{1,7}$, Bo Youn $\mathrm{Cho}^{8}$ and Young Joo Park ${ }^{1}$ \\ 'Department of Internal Medicine, Seoul National University College of Medicine, Seoul National University Hospital, Seoul, Korea, \\ ${ }^{2}$ Department of Internal Medicine, National Medical Center, Seoul, Korea, ${ }^{3}$ Department of Pathology, Seoul National University \\ College of Medicine, Seoul, Korea, ${ }^{4}$ Department of Internal Medicine, Kangwon National University Hospital, \\ Chuncheon, Korea, ${ }^{5}$ Department of Internal Medicine, Seoul National University Bundang Hospital, Seongnam, \\ Korea, ${ }^{6}$ Department of Internal Medicine, Seoul National University Boramae Medical Center, Seoul, Korea, \\ ${ }^{7}$ Korea National Institute of Health, Cheongju, Korea, and ${ }^{8}$ Department of Internal Medicine, Chung-Ang University \\ College of Medicine, Seoul, Korea \\ *(Y S Song and J A Lim contributed to this work) \\ Correspondence \\ should be addressed \\ to Y J Park \\ Email \\ yjparkmd@snu.ac.kr
}

\begin{abstract}
Objective: Changes in the clinicopathological characteristics and genetic alterations of follicular thyroid cancer (FTC) over time have not been reported. Moreover, the prognostic effects of RAS and TERT promoter mutations in FTC have not been clearly elucidated. We investigated changes in the clinicopathological characteristics of patients with FTC over four decades, as well as the clinical significance of genetic mutations of FTC.

Design and methods: This retrospective study included 690 patients with FTC who underwent thyroidectomy between 1973 and 2015 at the Seoul National University Hospital. In 134 samples, genetic tests for N/HIKRAS and TERT promoter mutations and PAX8/PPAR $\gamma$ rearrangement were performed.

Results: The age at diagnosis has increased $(P<0.001)$ in recent decades and extrathyroidal extension of the tumor has become less common $(P=0.033)$. Other clinicopathological characteristics and prognosis of FTC have not significantly changed. The prevalence of RAS mutations decreased $(P=0.042)$ over time, whereas that of TERT promoter mutations remained stable. RAS mutations were associated with distant metastasis and persistent disease, and TERT promoter mutations were associated with distant metastasis, advanced TNM stage, recurrence and disease-specific mortality. FTC patients with coexistent RAS and TERT promoter mutations showed a higher recurrence risk than those with only one mutation.

Conclusions: The age at diagnosis of FTC and the frequency of extrathyroidal extension have changed over four decades. Moreover, the prevalence of RAS mutations decreased. RAS and TERT promoter mutations may be associated with poor clinical outcomes in FTC, especially when the two mutations coexist.
\end{abstract}

\section{Introduction}

Follicular thyroid cancer (FTC) is the second most common type of thyroid malignancy following papillary thyroid cancer (PTC), which accounts for $10 \%-32 \%$ of cases of differentiated thyroid cancer (DTC) $(1,2)$. In the last decades, the incidence of thyroid cancer has
() 2017 European Society of Endocrinology Printed in Great Britain sharply increased worldwide. This trend was especially predominant for small PTC, which shows less aggressive features and favorable outcomes $(3,4)$. However, long-term trends in the characteristics and outcomes of FTC, distinct from other types of thyroid cancer, have not been reported. 
Several previous studies have presented temporal changes in the mutational frequencies associated with PTC. In the United States, the overall prevalence of $B R A F$ mutations was stable, but increased from $50.0 \%$ to $76.9 \%$ in conventional PTC over the last four decades (5). Moreover, RAS mutations increased from $2.7 \%$ to $24.9 \%$ due to an increase in follicular-variant PTC (FVPTC). In Europe, the frequency of $B R A F$ mutations increased gradually from $28.0 \%$ to $58.1 \%$ over the last 15 years (6). The incidence of the RET/PTC rearrangement, in contrast, decreased from $33.0 \%$ to $9.8 \%$ over the same period. In Korea, which is a BRAF mutation-prevalent country, BRAF-mutated PTCs increased from $62.2 \%$ to $73.7 \%$ over the last two decades (7). However, no study has evaluated changes in the mutational frequencies of FTC over time.

The most frequent genetic alterations in FTC are $R A S$ mutations and the PAX8/PPAR $\gamma$ rearrangement (8). The prognostic value of $R A S$ mutations is still unclear, although some evidence suggests that RAS-mutated FTCs may be at risk for a poor prognosis $(9,10)$ or distant metastasis $(11$, 12). Moreover, no evidence exists linking the PAX8/PPAR $\gamma$ rearrangement with clinical outcomes. However, recent studies have demonstrated that TERT promoter mutations, especially when they coexist with $B R A F$ mutations, are associated with a poor prognosis in PTC (13). Regarding the prognostic effect of the coexistence of TERT promoter and RAS mutations, we recently demonstrated for the first time that their coexistence may increase the risk of diseasespecific mortality and recurrence in DTC, including both PTC and FTC (14). However, the corresponding effect in FTC only has not been analyzed.

In this study, we investigated changes in the clinicopathological characteristics, prognosis and mutational profiles of FTC over four decades, as well as associations between genetic alterations and clinicopathological outcomes.

\section{Patients and methods}

\section{Patients and tissue samples}

This study included 690 consecutive patients with FTC (544 females and 146 males) who underwent thyroidectomy at Seoul National University Hospital (Seoul, Korea) between 1973 and 2015, and analyzed longterm trends in clinicopathological characteristics and prognoses. The median follow-up duration was 6.9 years (interquartile range, 3.6-11.6 years). The diagnosis of FTC was based on the postoperative pathology report, and clinicopathological data at baseline and during follow-up were collected retrospectively from their electronic medical records.

Among the FTC patients who underwent surgery in 1997-2003 and 2009-2012, genetic analyses were performed of 134 patients (67 patients in each period) whose formalin-fixed paraffin-embedded (FFPE) DNA samples were available, including 119 patients from our previous report (14). For the mutational analysis, all tissue samples were reviewed by an expert pathologist who specializes in thyroid pathology, and the FTC tumor region of the samples was microdissected for subsequent DNA extraction. Pathological diagnoses were made according to the latest World Health Organization classifications for thyroid cancer (15). This study was conducted according to the guidelines of the Declaration of Helsinki. The research protocol was approved by the institutional review board committee of the Seoul National University Hospital (H-1207-124-420).

\section{Mutational analyses}

All samples of the FFPE tumor block were digested with proteinase $\mathrm{K}$ (Sigma) for more than $24 \mathrm{~h}$ at $56^{\circ} \mathrm{C}$, and DNA was then isolated from the digested tissue using a Tissue SV Mini kit (General Biosystem Inc., Seoul, Korea). NRAS (codon 12/13 and codon 61), HRAS (codon 12/13 and codon 61), KRAS (codon 12/13 and codon 61) and TERT promoter (C228T and C250T) mutations were examined using polymerase chain reaction (PCR) and amplified using appropriate primers (Supplementary Table 1, see section on supplementary data given at the end of this article). PCR was performed using a BioMix kit (Bioline, Taunton, MA, USA). Purified PCR products obtained using a QIAquick Gel Extraction kit (Qiagen) were used for sequencing with a Big Dye Terminator Cycle Sequencing Ready Reaction kit (Applied Biosystems). The sequences were analyzed using ABI Prism 3730 Genetic Analyzer (Applied Biosystems). Each DNA sample was assayed at least twice in order to confirm its RAS and TERT promoter mutation status by sequencing with both forward and reverse primers. RAS mutation status was assessed in all 134 samples, but TERT promoter mutation status was only assessed in 120 samples because of PCR failure in 14 samples. To evaluate the PAX8/PPAR $\gamma$ rearrangement, we performed fluorescence in situ hybridization (FISH) analysis in FFPE tumor tissues using the PPAR $(3 \mathrm{p} 25)$ break probe (Kreatech Diagnostics, Amsterdam, The Netherlands). These commercially available probes are designed as a dual-color probe where the two regions cross the break-point (Supplementary Fig. 1). The FISH analysis 
could only be done in 48 cases (2010-2012), depending on the staining and preservation status of FFPE.

\section{Statistical analyses}

Data are presented as frequencies and percentages, as means and standard deviations or as medians and interquartile range. Categorical variables were compared with the Pearson chi-square test or the Fisher exact test (if the number was $<5$ ). The independent $t$ test or the WilcoxonMann-Whitney test was used for continuous variables. In order to compare trends of the clinicopathological characteristics of FTC over three periods, the linear-bylinear association test was used for categorical variables and analysis of variance for continuous variables. The log-rank test was used to compare variables based on the time of events. Cox proportional hazards regression was used to assess the risk of recurrence. Statistical significance was defined as two-sided $P$ values $<0.05$. All statistical analyses were performed with SPSS 20.0 (IBM Corp., Armonk, NY, USA).

\section{Results}

\section{Changes in clinicopathological characteristics and outcomes of FTC patients between 1973 and 2015}

The 690 patients with FTC were classified into three groups by the calendar year of diagnosis: 1973-1995 $(n=68)$, 1996-2005 $(n=231)$, and 2006-2015 ( $n=391$; Table 1$)$. The mean age of patients in 1973-1995 was significantly younger than those in other periods $(P<0.001)$, but there was no difference in age after 1995. Most of histological characteristics, including the size and proportion of widely invasive FTC, vascular invasion, multiplicity and lymph node metastasis, did not change over time. However, extrathyroidal extension, especially gross invasion, has decreased recently $(P=0.033)$. Although the overall incidence of distant metastasis decreased from $14.7 \%$ to $5.1 \%$, no significant difference was found in the survival analysis using the time from the beginning to the occurrence of an event (log-rank $P=0.346$ ). Moreover, the percentage of patients with distant metastasis at the initial presentation did not significantly vary over time. The most frequent sites of distant metastasis were lung and bone throughout the period. Unilateral lobectomy alone was common in 1973-1995, after which total thyroidectomy or lobectomy with completion thyroidectomy became more frequent, although there was no significant temporal trend $(P=0.179)$. The proportion of patients who received radioactive iodine (RAI) therapy, especially as a remnant ablation, increased over time $(P<0.001)$, but the total dose of RAI significantly decreased $(P<0.001)$. During the median follow-up of 6.9 years, $9.0 \%$ of the patients experienced persistent disease or tumor recurrence, and $2.2 \%$ died from FTC. No significant differences were found among time periods in the proportion of patients with no evidence of disease, persistence, recurrence or disease-specific mortality.

\section{Prevalence of RAS and TERT promoter mutations and the PAX8/PPAR $\gamma$ rearrangement in FTC}

None of the characteristics of the 134 patients who underwent genetic analysis were significantly different from the overall samples of the corresponding period (Supplementary Table 2). Among them, 43 (32.1\%) and 7 (5.8\%) patients had tumors with RAS and TERT promoter mutations respectively (Table 2 ). The prevalence of $R A S$ mutations decreased from $40.3 \%$ to $23.9 \%(P=0.042)$, and the HRAS codon 61 mutation mainly contributed to this decrease. The NRAS codon 61 mutation was most common in both periods. The codon 12/13 mutations of NRAS, HRAS and KRAS were not found. TERT promoter mutations in each period were found in three $(4.5 \%)$ and four $(7.4 \%)$ cases respectively $(P=0.699)$. The major type of TERT promoter mutation was TERT C228T in both periods, although TERT C250T was observed in one case in 2009-2012. The PAX8/PPAR $\gamma$ rearrangement was found in one $(2.1 \%)$ case in $2009-2012$.

\section{Clinicopathological characteristics and outcomes of FTC according to mutational status}

Comparing the clinicopathological features of FTC according to RAS mutational status (Table 3), distant metastasis occurred more frequently in RAS-mutated FTCs (log-rank $P=0.030$ ), even though other features did not differ between $R A S$ wild-type and RAS-mutated FTCs. $R A S$ mutations were significantly associated with a lower frequency of no evidence of disease (log-rank $P=0.011$ ) and a higher proportion of persistent disease $(P=0.037)$. However, no differences in recurrence or disease-specific mortality were found.

TERT promoter mutations were significantly associated with distant metastasis (log-rank $P=0.001$ ), in particular to the lung (log-rank $P=0.006$ ), and advanced TNM stage $(P=0.045$; Table 4$)$. Furthermore, the patients with a TERT promoter mutation tended to have a poor 


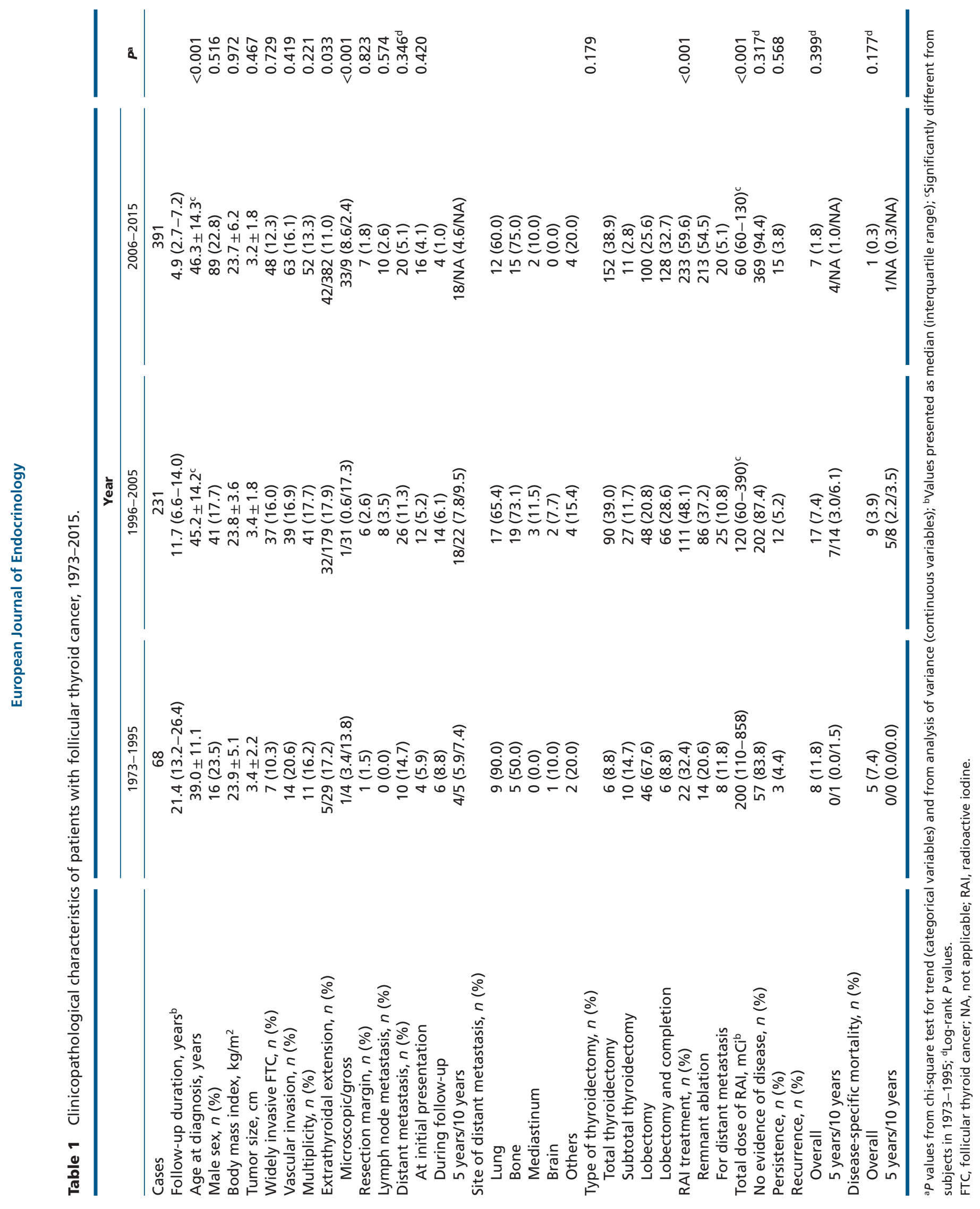


Table 2 Changes of mutational frequencies in follicular thyroid cancer between 1997-2003 and 2009-2012.

\begin{tabular}{l}
\hline \\
\hline Cases \\
RAS mutation, $n(\%)$ \\
NRAS codon 61 \\
HRAS codon 61 \\
KRAS codon 61 \\
N/H/KRAS codon 12,13 \\
TERT promoter mutation, \\
$n$ (\%) \\
C228T \\
C250T \\
PPAR rearrangement, \\
$n(\%)$
\end{tabular}

\begin{tabular}{|c|c|c|}
\hline \multicolumn{2}{|c|}{ Year } & \multirow[b]{2}{*}{$\boldsymbol{P}$} \\
\hline 1997-2003 & 2009-2012 & \\
\hline 67 & 67 & \\
\hline 27 (40.3) & $16(23.9)$ & 0.042 \\
\hline $19(28.4)$ & $14(20.9)$ & \\
\hline 8 (11.9) & $1(1.5)$ & \\
\hline $0(0.0)$ & $1(1.5)$ & \\
\hline $0(0.0)$ & $0(0.0)$ & \\
\hline $3 / 66$ (4.5) & $4 / 54(7.4)$ & 0.699 \\
\hline $3 / 66$ (4.5) & $3 / 54(5.6)$ & \\
\hline $0 / 66(0.0)$ & $1 / 54(1.9)$ & \\
\hline NA & $1 / 48(2.1)$ & NA \\
\hline
\end{tabular}

NA, not applicable. prognosis and were less likely to remain disease-free (logrank $P=0.001$ ). The percentage of patients with persistent disease was higher in the TERT promoter mutation group, although this was not statistically significant due to its low incidence. Moreover, the overall recurrence and disease-specific mortality rates in TERT promoter wildtype vs mutant samples were significantly different $(2.7 \%$ vs $28.6 \%$ and $0.9 \%$ vs $14.3 \%$, respectively) (log-rank $P$, for recurrence $=0.002$; for disease-specific mortality $=0.007$ ).

The only patient who showed the PAX8/PPAR rearrangement was a 39.1-year-old man at diagnosis who had an 8.0-cm minimally invasive FTC without lymph node or distant metastasis. He underwent a lobectomy with completion thyroidectomy following RAI therapy $(120 \mathrm{mCi})$ for remnant ablation and showed no tumor recurrence during 7.4 years of follow-up.

Table 3 Clinicopathological characteristics and outcomes of follicular thyroid cancer according to the mutational status of RAS.

\begin{tabular}{|c|c|c|c|}
\hline & & & \\
\hline & Wild type & Mutant & $P$ \\
\hline Cases, $n(\%)$ & $91(67.9)$ & $43(32.1)$ & \\
\hline Follow-up duration, years ${ }^{a}$ & $6.5(4.5-13.3)$ & $6.1(4.5-13.4)$ & \\
\hline RAS mutation type, $n(\%)$ & & & \\
\hline N/H/KRAS & - & $33 / 9 / 1(24.6 / 6.7 / 0.7)$ & 0.002 \\
\hline Age at diagnosis, years & $45.9 \pm 14.4$ & $42.7 \pm 13.0$ & 0.223 \\
\hline Male sex, $n(\%)$ & $21(23.1)$ & $9(20.9)$ & 0.781 \\
\hline Body mass index, $\mathrm{kg} / \mathrm{m}^{2}$ & $24.4 \pm 3.6$ & $23.9 \pm 3.9$ & 0.470 \\
\hline Tumor size $(\mathrm{cm})$ & $3.6 \pm 2.0$ & $3.2 \pm 1.3$ & 0.267 \\
\hline Widely invasive FTC, $n(\%)$ & $16(17.6)$ & $7(16.3)$ & 0.852 \\
\hline Vascular invasion, $n(\%)$ & $20(22.0)$ & $7(16.3)$ & 0.443 \\
\hline Multiplicity, $n(\%)$ & $11(12.1)$ & $5(11.6)$ & 0.939 \\
\hline Extrathyroidal extension, $n(\%)$ & $15(17.9)$ & $6(15.8)$ & 0.779 \\
\hline Microscopic/gross & $6 / 9(7.1 / 10.7)$ & $1 / 5(2.6 / 13.2)$ & \\
\hline Resection margin, $n(\%)$ & $2(2.2)$ & $2(4.7)$ & 0.593 \\
\hline Lymph node metastasis, $n(\%)$ & $1(1.1)$ & $2(4.7)$ & 0.241 \\
\hline Distant metastasis, $n(\%)$ & $3(3.3)$ & $6(14.0)$ & $0.030^{\mathrm{b}}$ \\
\hline At initial presentation & $0(0.0)$ & $3(7.0)$ & 0.031 \\
\hline During follow-up & $3(3.3)$ & $3(7.0)$ & \\
\hline 5 years $/ 10$ years & $2 / 2(2.2 / 2.2)$ & $3 / 4(7.0 / 9.3)$ & \\
\hline Site of distant metastasis, $n(\%)$ & & & \\
\hline Lung & $3(3.3)$ & $3(7.0)$ & 0.385 \\
\hline Bone & $1(1.1)$ & $3(7.0)$ & 0.097 \\
\hline Other sites & $1(1.1)$ & $1(2.6)$ & \\
\hline TNM stage, $n(\%)$ & & & 0.644 \\
\hline I-II/ III-IV & $73 / 18(80.2 / 19.8)$ & $33 / 10(76.7 / 23.3)$ & \\
\hline No evidence of disease, $n(\%)$ & $88(96.7)$ & $36(83.7)$ & $0.011^{b}$ \\
\hline Persistence, $n(\%)$ & $1(1.1)$ & $4(9.3)$ & 0.037 \\
\hline Recurrence, $n(\%)$ & & & \\
\hline Overall & $2(2.2)$ & $3(7.0)$ & $0.195^{b}$ \\
\hline 5 years $/ 10$ years & $1 / 2(1.1 / 2.2)$ & $1 / 2(2.3 / 4.7)$ & \\
\hline Disease-specific mortality, $n(\%)$ & & & \\
\hline Overall & $1(1.1)$ & $1(2.3)$ & $0.572^{b}$ \\
\hline 5 years $/ 10$ years & $1 / 1(1.1 / 1.1)$ & $1 / 1(2.3 / 2.3)$ & \\
\hline
\end{tabular}


Table 4 Clinicopathological characteristics and outcomes of follicular thyroid cancer according to the mutational status of TERT promoter.

\begin{tabular}{|c|c|c|c|}
\hline & \multicolumn{2}{|c|}{ TERT } & \multirow[b]{2}{*}{$\boldsymbol{P}$} \\
\hline & Wild type & Mutant & \\
\hline Cases, $n(\%)$ & $113(94.2)$ & $7(5.8)$ & \\
\hline Follow-up duration, years ${ }^{a}$ & $6.7(4.9-13.5)$ & $6.4(4.5-14.3)$ & \\
\hline \multicolumn{4}{|l|}{ TERT mutation type, $n(\%)$} \\
\hline C228T/C250T & - & $6 / 1(5.0 / 0.8)$ & 0.002 \\
\hline Age at diagnosis, years & $44.6 \pm 14.2$ & $51.9 \pm 15.7$ & 0.191 \\
\hline Male sex, $n(\%)$ & $24(21.2)$ & $2(28.6)$ & 0.644 \\
\hline Body mass index, $\mathrm{kg} / \mathrm{m}^{2}$ & $24.3 \pm 3.8$ & $22.6 \pm 3.5$ & 0.290 \\
\hline Tumor size $(\mathrm{cm})$ & $3.5 \pm 1.8$ & $4.8 \pm 2.6$ & 0.071 \\
\hline Widely invasive FTC, $n(\%)$ & $22(19.5)$ & $1(14.3)$ & 1.000 \\
\hline Vascular invasion, $n(\%)$ & $22(19.5)$ & $3(42.9)$ & 0.157 \\
\hline Multiplicity, $n(\%)$ & $13(11.5)$ & $1(14.3)$ & 0.590 \\
\hline Extrathyroidal extension, $n(\%)$ & $21(20.8)$ & $0(0.0)$ & 0.341 \\
\hline Microscopic/gross & $7 / 14(6.9 / 13.9)$ & $0 / 0(0.0 / 0.0)$ & \\
\hline Resection margin, $n(\%)$ & $4(3.5)$ & $0(0.0)$ & 1.000 \\
\hline Lymph node metastasis, $n(\%)$ & $1(0.9)$ & $1(14.3)$ & 0.114 \\
\hline Distant metastasis, $n(\%)$ & $6(5.3)$ & $3(42.9)$ & $0.001^{b}$ \\
\hline At initial presentation & $2(1.8)$ & $1(14.3)$ & 0.166 \\
\hline During follow-up & $4(3.5)$ & $2(28.6)$ & \\
\hline 5 years $/ 10$ years & $4 / 4(3.5 / 3.5)$ & $1 / 2(14.3 / 28.6)$ & \\
\hline \multicolumn{4}{|l|}{ Site of distant metastasis, $n(\%)$} \\
\hline Lung & $4(3.5)$ & $2(28.6)$ & 0.039 \\
\hline Bone & $3(2.7)$ & $1(14.3)$ & 0.216 \\
\hline Other sites & $1(0.9)$ & $1(14.3)$ & \\
\hline TNM stage, $n(\%)$ & & & 0.045 \\
\hline I-II/ III-IV & $90 / 23(79.6 / 20.4)$ & $3 / 4(42.9 / 57.1)$ & \\
\hline No evidence of disease, $n(\%)$ & $106(93.8)$ & $4(57.1)$ & $0.001^{b}$ \\
\hline Persistence, $n(\%)$ & $4(3.5)$ & $1(14.3)$ & 0.263 \\
\hline \multicolumn{4}{|l|}{ Recurrence, $n(\%)$} \\
\hline Overall & $3(2.7)$ & $2(28.6)$ & $0.002^{b}$ \\
\hline 5 years $/ 10$ years & $2 / 2(1.8 / 1.8)$ & $0 / 1(0.0 / 14.3)$ & \\
\hline \multicolumn{4}{|l|}{ Disease-specific mortality, $n(\%)$} \\
\hline Overall & $1(0.9)$ & $1(14.3)$ & $0.007^{b}$ \\
\hline 5 years/10 years & $1 / 1(0.9 / 0.9)$ & $1 / 1(14.3 / 14.3)$ & \\
\hline
\end{tabular}

aValues presented as median (interquartile range).

bog-rank $P$ values.

\section{Association between the RAS and TERT promoter mutations and the effect of their coexistence on FTC recurrence}

A significant association of $R A S$ mutations with TERT promoter mutations was observed $(P=0.045$; Supplementary Table 3). TERT promoter mutations were found in $2.5 \%$ of $R A S$ wild-type cases vs $12.2 \%$ of
RAS-mutated cases, and conversely, RAS mutations were found in $31.9 \%$ of TERT wild-type cases vs $71.4 \%$ of TERTmutated cases.

The patients with a $R A S$ mutation, especially with coexistent RAS and TERT promoter mutations, showed higher rates of recurrence or persistence than those without any mutations (Table 5). Two patients had a TERT

Table 5 Hazard ratios of RAS and TERT promoter mutations for recurrence of follicular thyroid cancer.

\begin{tabular}{|c|c|c|c|c|c|c|c|c|c|}
\hline & & & & & Unadjusted & & & Adjusted $^{a}$ & \\
\hline Mutation status & Cases & Recurrence/persistence, $\boldsymbol{n}(\%)$ & Recurrence, $\boldsymbol{n}(\%)$ & HR & $95 \% \mathrm{Cl}$ & $\boldsymbol{P}$ & HR & $95 \% \mathrm{Cl}$ & $\boldsymbol{P}$ \\
\hline$R A S(-)$ TERT(-) & 77 & $3(3.9)$ & $2(2.6)$ & 1 & & & 1 & & \\
\hline$R A S(+) T E R T(-)$ & 36 & $4(11.1)$ & $1(2.8)$ & 1.13 & $0.10-12.46$ & 0.922 & 2.86 & $0.21-39.57$ & 0.433 \\
\hline$R A S(-)$ TERT(+) & 2 & $0(0.0)$ & $0(0.0)$ & - & & & - & & \\
\hline$R A S(+) T E R T(+)$ & 5 & $3(60.0)$ & $2(40.0)$ & 13.59 & $1.88-98.55$ & 0.010 & 6.27 & $0.76-51.68$ & 0.088 \\
\hline
\end{tabular}


promoter mutation alone, and FTC recurrence was not observed in them. The coexistence of two mutations had the highest recurrence rate and increased the recurrence risk 6.27-fold compared to the absence of mutations, although statistical significance was lost after adjustment for age at diagnosis and sex.

\section{Discussion}

The age at the diagnosis of FTC increased in the late 1990s, and the extrathyroidal extension of tumors significantly decreased recently. Moreover, the prevalence of $R A S$ mutations also decreased in recent years, while that of TERT promoter mutations did not change. RAS mutations were associated with distant metastasis, persistent disease and frequent TERT promoter mutations. The coexistence of $R A S$ and TERT promoter mutations was associated with a higher rate of recurrence, suggesting that they had additive effects on the prognosis, similarly to BRAF and TERT promoter mutations $(13,14)$.

The increase in small and low-risk PTCs has been attributed to the recent increase in thyroid cancer screening with ultrasonography $(3,16)$. In our study, the older age at the diagnosis of FTC after the late 1990s might be attributed to the introduction of a cancer screening program in the late 1990s. However, most other clinicopathological characteristics, including tumor size, were unchanged over time. This is because FTC usually does not have specific suspicious features of malignancy on ultrasonography (17), and in such cases, fine-needle aspiration (FNA) is usually performed when the nodular size is larger than $1-2 \mathrm{~cm}(18,19)$. Furthermore, because FNA cannot distinguish between follicular adenoma and carcinoma on the basis of cytology, surgery is not immediately performed in some wait-and-see cases. However, a possible improvement in the aggressiveness of FTC was found; the total frequency of extrathyroidal extension decreased despite recent advances in pathologic evaluation. Recent increases in microscopic extensions might be related to more cautious pathologic examinations; however, gross extensions became markedly less common in the most recent decade, which may suggest a prognostic improvement in recently diagnosed FTCs. We propose more long-term observations to clarify this.

Recently, next-generation sequencing (NGS) has improved our understanding of the genetics and biology of thyroid cancer, including FTC and PTC $(20,21,22)$, and $R A S$ point mutations are the most representative driver mutations in FTC. As the results of our study, $R A S$ mutations have been reported to be associated with distant metastasis $(11,12)$ and poor prognoses in FTC $(9,10)$. This prognostic impact of RAS mutations on FTC seems to be in contrast to the favorable prognosis of PTC with RAS mutations, which is usually FVPTC without aggressive tumor behavior $(23,24)$. Moreover, a similar frequency of $R A S$ mutations was also observed in follicular adenoma $(20,25)$. Therefore, we suggest that the same RAS mutations might play different prognostic roles depending on the type of cancer.

Interestingly, as was found for BRAF mutations in PTC, $R A S$ mutations were also associated with TERT promoter mutations in FTC, and their coexistence was associated with worse prognoses. TERT promoter mutations have not been detected in benign thyroid nodules, and have only uncommonly been found in cancer with a benign nature (26). In this study, patients with TERT-mutated FTC showed more frequent instances of distant metastasis, and higher recurrence and mortality. Although we could not demonstrate the effects of TERT promoter mutations alone, when they coexisted with a RAS mutation, the hazard ratio of recurrence was increased by more than 6 times (Table 5). Thus, TERT could be a useful prognostic marker of malignancy, especially for RAS-mutated follicular neoplasm.

The prevalence of the PAX8/PPAR $\gamma$ rearrangement has been found to vary geographically, ranging from $0 \%$ to $57 \%$ of FTCs (27); notably, a Japanese study failed to identify a single PAX8/PPAR $\gamma$ rearrangement in FTC (28). Its prevalence in Asia has been reported to be lower than that in other regions, but this is not conclusive because of the small number of studies in Asia. In this study, we observed a similarly low frequency of the PAX8/PPAR $\gamma$ rearrangement in FTC $(2.1 \%)$.

Regarding other oncogenes of FTC not tested in this study, Nikiforova et al. (29) tested 12 cancer genes using targeted sequencing panel in 36 FTCs and identified that the second most common mutations after $R A S(n=12)$ were TSHR $(n=4)$ and TP53 $(n=4)$ mutations in conventional and oncocytic FTCs, respectively. However, in the two recently published studies of FTC genomics in Korea using a NGS approach, including a study of our institute $(20,22)$, the prevalence of TSHR and TP53 mutations were relatively very low: there was no FTC patient harboring TSHR mutation in both studies, and only one of 30 patients (3.3\%) with TP53 mutation who had a favorable prognosis in our study (20). Moreover, according to the recent NGS studies on anaplastic or poorly differentiated thyroid cancer $(30,31)$, TP53, unlike TERT, might be 
related to the aggressiveness of undifferentiated thyroid cancer rather than well-differentiated thyroid cancer.

Our study had some limitations. Genetic testing was not performed in consecutive patients because of the limited availability of FFPE samples (14). Nevertheless, the characteristics of FTC samples performed genetic testing were not significantly different from the overall samples of FTC in the corresponding periods of our study, which could be representative. Regarding the histologic report, some FVPTC cases could have been included in the past, because FVPTC was first described in 1953 (32) and broadly recognized in the mid-1970s $(33,34)$, and more detailed examinations have been performed in recent decades.

Notwithstanding these limitations, to the best of our knowledge, this study is the first comprehensive study of the long-term changes in the characteristics and prognosis of FTC. In addition, the clinicopathological variables were extensively examined in all subjects, which might be useful for evaluating the effects of RAS and TERT promoter mutations on the clinical outcomes of FTC.

In conclusion, the age at diagnosis of FTC and the frequency of extrathyroidal extension have changed over the last four decades. Moreover, the prevalence of RAS mutations decreased. RAS mutations may be associated with poor clinical outcomes in FTC, especially in coexistence with TERT promoter mutations.

\section{Supplementary data}

This is linked to the online version of the paper at http://dx.doi.org/10.1530/ EJE-17-0456.

\section{Declaration of interest}

The authors declare that there is no conflict of interest that could be perceived as prejudicing the impartiality of this study.

\section{Funding}

This research was supported by the Seoul National University Hospital and the Seoul National University College of Medicine Research Fund (grant number 800-20120032).

\section{References}

1 Hundahl SA, Cady B, Cunningham MP, Mazzaferri E, McKee RF, Rosai J, Shah JP, Fremgen AM, Stewart AK \& Holzer S. Initial results from a prospective cohort study of 5583 cases of thyroid carcinoma treated in the united states during 1996. U.S. and German Thyroid Cancer Study Group. An American College of Surgeons Commission on cancer patient care evaluation study. Cancer 2000 89 202-217. (doi:10.1002/1097-0142(20000701)89:1<202::AIDCNCR27>3.0.CO;2-A)
2 Lin JD, Huang MJ, Juang JH, Chao TC, Huang BY, Chen KW, Chen JY, Li KL, Chen JF \& Ho YS. Factors related to the survival of papillary and follicular thyroid carcinoma patients with distant metastases. Thyroid 19999 1227-1235. (doi:10.1089/thy.1999.9.1227)

3 Ho AS, Davies L, Nixon IJ, Palmer FL, Wang LY, Patel SG, Ganly I, Wong RJ, Tuttle RM \& Morris LG. Increasing diagnosis of subclinical thyroid cancers leads to spurious improvements in survival rates. Cancer 2015121 1793-1799. (doi:10.1002/cncr.29289)

4 Cho BY, Choi HS, Park YJ, Lim JA, Ahn HY, Lee EK, Kim KW, Yi $\mathrm{KH}$, Chung JK, Youn YK et al. Changes in the clinicopathological characteristics and outcomes of thyroid cancer in Korea over the past four decades. Thyroid 201323 797-804. (doi:10.1089/thy.2012.0329)

5 Jung CK, Little MP, Lubin JH, Brenner AV, Wells SA Jr, Sigurdson AJ \& Nikiforov YE. The increase in thyroid cancer incidence during the last four decades is accompanied by a high frequency of BRAF mutations and a sharp increase in RAS mutations. Journal of Clinical Endocrinology and Metabolism 201499 E276-E285. (doi:10.1210/ jc.2013-2503)

6 Romei C, Fugazzola L, Puxeddu E, Frasca F, Viola D, Muzza M, Moretti S, Nicolosi ML, Giani C, Cirello V et al. Modifications in the papillary thyroid cancer gene profile over the last 15 years. Journal of Clinical Endocrinology and Metabolism 201297 E1758-E1765. (doi:10.1210/ jc.2012-1269)

7 Hong AR, Lim JA, Kim TH, Choi HS, Yoo WS, Min HS, Won JK, Lee KE, Jung KC, Park DJ et al. Clinical implications of the BRAF(V600E) mutation in papillary thyroid cancer patients in Korea over the past two decades. Endocrinology and Metabolism 201429 505-513. (doi:10.3803/EnM.2014.29.4.505)

8 Nikiforova MN, Lynch RA, Biddinger PW, Alexander EK, Dorn GW 2nd, Tallini G, Kroll TG \& Nikiforov YE. RAS point mutations and PAX8-PPAR gamma rearrangement in thyroid tumors: evidence for distinct molecular pathways in thyroid follicular carcinoma. Journal of Clinical Endocrinology and Metabolism 200388 2318-2326. (doi:10.1210/jc.2002-021907)

9 Fukahori M, Yoshida A, Hayashi H, Yoshihara M, Matsukuma S, Sakuma Y, Koizume S, Okamoto N, Kondo T, Masuda M et al. The associations between RAS mutations and clinical characteristics in follicular thyroid tumors: new insights from a single center and a large patient cohort. Thyroid 201222 683-689. (doi:10.1089/thy.2011.0261)

10 Garcia-Rostan G, Zhao H, Camp RL, Pollan M, Herrero A, Pardo J, Wu R, Carcangiu ML, Costa J \& Tallini G. RAS mutations are associated with aggressive tumor phenotypes and poor prognosis in thyroid cancer. Journal of Clinical Oncology 200321 3226-3235. (doi:10.1200/ JCO.2003.10.130)

11 Jang EK, Song DE, Sim SY, Kwon H, Choi YM, Jeon MJ, Han JM, Kim WG, Kim TY, Shong YK et al. NRAS codon 61 mutation is associated with distant metastasis in patients with follicular thyroid carcinoma. Thyroid 201424 1275-1281. (doi:10.1089/thy.2014.0053)

12 Manenti G, Pilotti S, Re FC, Della Porta G \& Pierotti MA. Selective activation of ras oncogenes in follicular and undifferentiated thyroid carcinomas. European Journal of Cancer 1994 30A 987-993. (doi:10.1016/0959-8049(94)90130-9)

13 Xing M, Liu R, Liu X, Murugan AK, Zhu G, Zeiger MA, Pai S \& Bishop J. BRAF V600E and TERT promoter mutations cooperatively identify the most aggressive papillary thyroid cancer with highest recurrence. Journal of Clinical Oncology 201432 2718-2726. (doi:10.1200/ JCO.2014.55.5094)

14 Song YS, Lim JA, Choi H, Won JK, Moon JH, Cho SW, Lee KE, Park YJ, Yi KH, Park do J et al. Prognostic effects of TERT promoter mutations are enhanced by coexistence with BRAF or RAS mutations and strengthen the risk prediction by the ATA or TNM staging system in differentiated thyroid cancer patients. Cancer 2016122 1370-1379. (doi:10.1002/cncr.29934)

15 DeLellis R, Lloyd R, Heitz P \& Eng C, eds. WHO Classification of Tumors, Pathology and Genetics - Tumors of Endocrine Organs. Lyon: IARC Press, 2004. 
16 Choi H, Lim JA, Ahn HY, Cho SW, Lee KE, Kim KW, Yi KH, Sung MW, Youn YK, Chung JK et al. Secular trends in the prognostic factors for papillary thyroid cancer. European Journal of Endocrinology 2014171 667-675. (doi:10.1530/EJE-14-0225)

17 Hoang JK, Lee WK, Lee M, Johnson D \& Farrell S. US Features of thyroid malignancy: pearls and pitfalls. Radiographics $2007 \mathbf{2 7}$ 847-860. (doi:10.1148/rg.273065038)

18 American Thyroid Association Guidelines Taskforce on Thyroid N, Differentiated Thyroid C, Cooper DS, Doherty GM, Haugen BR, Kloos RT, Lee SL, Mandel SJ, Mazzaferri EL, McIver B et al. Revised American Thyroid Association management guidelines for patients with thyroid nodules and differentiated thyroid cancer. Thyroid 200919 1167-1214. (doi:10.1089/thy.2009.0110)

19 Haugen BR, Alexander EK, Bible KC, Doherty GM, Mandel SJ, Nikiforov YE, Pacini F, Randolph GW, Sawka AM, Schlumberger M et al. 2015 American Thyroid Association Management Guidelines for adult patients with thyroid nodules and differentiated thyroid cancer: the American Thyroid Association Guidelines task force on thyroid nodules and differentiated thyroid cancer. Thyroid 201626 1-133. (doi:10.1089/thy.2015.0020)

20 Yoo SK, Lee S, Kim SJ, Jee HG, Kim BA, Cho H, Song YS, Cho SW, Won JK, Shin JY et al. Comprehensive analysis of the transcriptional and mutational landscape of follicular and papillary thyroid cancers. PLOS Genetics 201612 e1006239. (doi:10.1371/journal.pgen.1006239)

21 Cancer Genome Atlas Research N. Integrated genomic characterization of papillary thyroid carcinoma. Cell 2014159 676-690. (doi:10.1016/j.cell.2014.09.050)

22 Jung SH, Kim MS, Jung CK, Park HC, Kim SY, Liu J, Bae JS, Lee SH, Kim TM, Lee SH et al. Mutational burdens and evolutionary ages of thyroid follicular adenoma are comparable to those of follicular carcinoma. Oncotarget 20167 69638-69648. (doi:10.18632/ oncotarget.11922)

23 Medici M, Kwong N, Angell TE, Marqusee E, Kim MI, Frates MC, Benson CB, Cibas ES, Barletta JA, Krane JF et al. The variable phenotype and low-risk nature of RAS-positive thyroid nodules. BMC Medicine 201513 184. (doi:10.1186/s12916-015-0419-z)

24 Xing M. Clinical utility of RAS mutations in thyroid cancer: a blurred picture now emerging clearer. BMC Medicine 20161412. (doi:10.1186/s12916-016-0559-9)
25 Sobrinho-Simoes M, Eloy C, Magalhaes J, Lobo C \& Amaro T. Follicular thyroid carcinoma. Modern Pathology 201124 (Supplement 2) S10-S18. (doi:10.1038/modpathol.2010.133)

26 Vinagre J, Almeida A, Populo H, Batista R, Lyra J, Pinto V, Coelho R, Celestino R, Prazeres H, Lima L et al. Frequency of TERT promoter mutations in human cancers. Nature Communications 201342185. (doi:10.1038/ncomms3185)

27 Song YS, Lim JA \& Park YJ. Mutation profile of well-differentiated thyroid cancer in Asians. Endocrinology and Metabolism 201530 252-262. (doi:10.3803/EnM.2015.30.3.252)

28 Hibi Y, Nagaya T, Kambe F, Imai T, Funahashi H, Nakao A \& Seo H. Is thyroid follicular cancer in Japanese caused by a specific $\mathrm{t}(2 ; 3)(\mathrm{q} 13 ; \mathrm{p} 25)$ translocation generating Pax8-PPAR gamma fusion mRNA? Endocrine Journal 200451 361-366. (doi:10.1507/ endocrj.51.361)

29 Nikiforova MN, Wald AI, Roy S, Durso MB \& Nikiforov YE. Targeted next-generation sequencing panel (ThyroSeq) for detection of mutations in thyroid cancer. Journal of Clinical Endocrinology and Metabolism 201398 E1852-E1860. (doi:10.1210/jc.2013-2292)

30 Kunstman JW, Juhlin CC, Goh G, Brown TC, Stenman A, Healy JM, Rubinstein JC, Choi M, Kiss N, Nelson-Williams C et al. Characterization of the mutational landscape of anaplastic thyroid cancer via whole-exome sequencing. Human Molecular Genetics 2015 24 2318-2329. (doi:10.1093/hmg/ddu749)

31 Landa I, Ibrahimpasic T, Boucai L, Sinha R, Knauf JA, Shah RH, Dogan S, Ricarte-Filho JC, Krishnamoorthy GP, Xu B et al. Genomic and transcriptomic hallmarks of poorly differentiated and anaplastic thyroid cancers. Journal of Clinical Investigation 2016126 1052-1066. (doi:10.1172/JCI85271)

32 Crile G Jr \& Hazard JB. Relationship of the age of the patient to the natural history and prognosis of carcinoma of the thyroid. Annals of Surgery 1953138 33-38. (doi:10.1097/00000658-195307000-00005)

33 Lindsay S. Carcinoma of the Thyroid Gland: A Clinical and Pathologic Study of 293 Patients at the University of California Hospital. Springfield, Illinois: Charles C Thomas Publisher, 1960.

34 Chem KT \& Rosai J. Follicular variant of thyroid papillary carcinoma: a clinicopathologic study of six cases. American Journal of Surgical Pathology 19771 123-130. (doi:10.1097/00000478197706000-00003)

Received 6 June 2017

Revised version received 27 July 2017

Accepted 1 September 2017 